\title{
LA REALIDAD COMO SIGNIFICANTE EN LA CONSTRUCCIÓN DE SIGNIFICADOS: UNA RESPONSABILIDAD POLÍTICA DE LA LINGÜÍSTICA*
}

\author{
Claudia ARCILA ROJas**
}

Fecha de recepción: 28 de octubre de 2010 • Fecha de aceptación: 24 de noviembre de 2010

\section{Resumen}

Por ser la realidad el episodio de experiencia dentro de la historia individual y/o colectiva que compromete con el día a día de habitabilidad y simbolismo en la concepción y práctica de la vida, se hace necesario particularizarla como ente material en devenir social, cultural, ambiental, económico y político, para acceder a nuevas formas de nominación que logren ser coherentes con el acontecer íntimo de este fenómeno. Es por ello que todo acto de habla está comprometido con la diferenciación entre verdad y realidad para no reducir arbitrariamente el hecho del conocimiento a determinismos que sirven de patrón en el acercamiento e indagación de las razones de estudio. La realidad comporta una complejidad distinta, y por ende, un sistema de enunciación que logre, primero, componer arqueológicamente los elementos que entran en juego en la configuración dialéctica de la cotidianidad, para proceder a divulgar, en compromiso ético y político, las circunstancias propias del contexto y su impacto en los sujetos que allí se desenvuelven.

* Documento producto del proyecto investigativo de tesis doctoral Una mirada desde el prisma filosófico de José Ortega y Gasset a la figura poética de Simón Bolívar en Mi delirio sobre el Chimborazo. Investigación en proceso, financiada por la Universidad Pontificia Bolivariana para conceder el título de doctora en Filosofía a Claudia Arcila Rojas, autora del texto e investigadora única del proyecto..

** Filósofa de la Universidad de Antioquia, Especialista en docencia investigativa universitaria de la Fundación Universitaria Luis Amigó y aspirante a doctora en Filosofía de la Universidad Pontificia Bolivariana. Docente investigadora Universidad San Buenaventura, Facultad de Educación; adscrita al Grupo de Investigación en Lenguaje y Comunicación _Grilec_corpecom@gmail.com. 
El presente texto acentúa en las evidencias de la discrepancia entre las leyes de la naturaleza y las de la sociedad, que implica agudizar el compromiso lingüístico para resistirse y atacar a la impunidad, que representa el rostro demacrado del mito, en sus expresiones de mentira y engaño.

Palabras clave: realidad, verdad, conocimiento, axiología, política, discurso.

\section{Abstract}

As reality be the episode of experience within the individual and / or group history that engages with the day to day livability and symbolism in the concept and practice of life, it is necessary to particularize it as material beings in social, cultural, environmental, economic and political evolution, to access new nomination forms that manage to be consistent with the intimate events of this phenomenon. That is why any speech act is committed with the distinction between truth and reality in order not to arbitrarily reduce the fact of knowledge to serve certain pattern in the approach and investigation of the reasons for study. The reality involves a different complexity, and therefore, a system of enunciation that ensure, first, the elements that compose archaeologically come into play in the dialectics of everyday settings, to proceed to disclose, in ethical and political commitment, the circumstances context and its impact on the subjects that there are developed.

This text stresses on the evidence of the discrepancy between the laws of nature and society, which involves sharpening the linguistic commitment to resisting and attacking impunity, which represents the haggard face of the myth, in their expressions of lies and deception.

Keywords: Reality, truth, knowledge, axiology, political, speech. 


\section{INTRODUCCIÓN}

Desde la particular y auténtica significación terminológica que cobra cada palabra en el suceso lingüístico al transitar hacia el discurso, se hace inexcusable el criterio de la precisión inherente al propósito conceptual de la definición. Definir es una facultad de la razón que dispone en la idea la unidad de lo dicho y lo visto como elevada composición entre el significado y el significante.

Ahora bien, es importante delimitar esta conjunción de lo enunciativo y lo sensible, ya que la aseveración de que todo lo nombrable ha de ser perceptible, puede desembocar en una ligereza positivista que en nada contribuye a la concepción ilustrativa de la palabra en su sentido declarativo de la verdad y sospechoso de la mentira.

La sucesión de palabras que componen un discurso, comporta una complejidad superior en el hecho de que la percepción, no solamente puede llegar a ser insuficiente en la captación de los datos que expresan la esencia misma de un evento, sino además, porque juegan intenciones de ensombrecimiento, a partir de las cuales se actualiza la función del mito en su connotación de soporte y razón externa de lo existente, que desconoce las leyes del desarrollo de la materia, y por ende, el carácter dialéctico de las dinámicas y relaciones que en ella se enmarcan.

Esto significa que se degrada la significación que tuvo el mito en el momento originario de la pregunta por el universo, reemplazándose su ser de primera imagen cognitiva por la mentira y el engaño que ella engendra, con lo cual ya no se trata del desconocimiento de las lógicas de la naturaleza física e histórica, sino de su negación.

Y es aquí justamente donde radica la responsabilidad política del lenguaje humano al poner las palabras en el molde de los hechos que pronuncian la realidad, y que son suficientes como evidencias y testimonios que hacen de la versión el enunciado de la verdad en su trayecto cognitivo y ético, al adoptar el objeto para ser analizado y conducido por la reflexión del pensamiento, y posteriormente, depurado por el entendimiento, encargado de entregar la idea al habla para que su acto sea el testigo veraz de lo acontecido.

En el campo del Derecho, esta acción tiene un impacto de inconmensurable trascendencia, puesto que la verdad, en su asiento etimológico 
veritas, convoca no simplemente el carácter verosímil de lo expuesto, sino también a los elementos de la verificación, desde los cuales la verdad niega esa aparente pasividad de traducir lo visto, para entenderse como una composición que reitera en sus análisis, pero además averigua e indaga los pormenores que se han difuminado en el carácter dinámico de la existencia. Además, la consideración jurídica de la axiología, se empeña en la teorización y la práctica de la justicia como piedra angular de veredictos fieles al cimiento de lo verdadero, en cuya versión las decisiones se apoyan.

También aquí la Lingüística es la indiscutible mediadora que no escatima en belleza y contundencia para hacer relucir la verdad que promete. $\mathrm{El}$ arte y el derecho de la palabra, lejos de ser el material para el artificio y la accidentalidad de atributos, fundamenta la inapreciable bondad del concepto al ser el embajador del objeto, del evento y de las circunstancias, en tanto ellos constituyan una ausencia temporal o definitiva frente a la constatación de los sentidos.

Ante dicha eventualidad, la palabra restituye, en su acto fonético, la imagen física o histórica que pasará a ser diseño mental de los escudriñamientos que su enunciación suscite, ya que la verdad, al no ser una entidad absoluta, no le es lícito negar el ingreso de la pregunta para diseminar la acción de justicia.

Es por ello que lo verdadero precede la comprensión de lo real, en tanto la omisión de los criterios que delimitan la verdad impiden entender el desarrollo de la realidad, puesto que en ella, la mentira amplía sus tentáculos en la dominación, negándole al hombre el derecho a resistirse a ciertos órdenes, donde lo real constituye una imposición arbitraria, enmascarada por la retórica y los oscuros oficios.

La verdad no es un dogma, así como lo real no es inmóvil, en ambos el mundo de los entes referencia una marea de tensiones y opuestos que se repelen o se complementan, de acuerdo a los principios que los constituyen. En el ámbito humano, por ejemplo, en cuyas relaciones el ambiente social es la expresión de los pilares políticos y económicos, se puede apreciar un desarrollo histórico en la lucha de antagónicos que hace legítimo el derecho a la oposición frente a modelos de realidad que han enclaustrado la verdad para someter en la supersticiosa sentencia de la obediencia a un destino. 
En este orden de ideas, la realidad, en tanto auspiciada por el 'amangualamiento' amoral y ambicioso de hombres y regímenes sin conciencia axiológica, no solo ha de ser cuestionada, sino divulgada en el verdadero contenido de sus significados, para reivindicar el derecho a la libertad como condición política que favorece la actuación en una experiencia de vida justa y digna.

"La fuerza de los sucesos y de las cosas" (Bolívar, 1971, p. 160) prensa la realidad a una perspectiva de consideraciones y coincidencias históricas que presuponen el análisis riguroso de sus causas para comprender el alcance de sus impactos. La realidad, a diferencia de la verdad, impele a quienes la experimentan a recorrer el círculo de las reiteraciones de su esencia, es decir, a transitar el camino de la historia para evidenciar en ella una constante social, marcando distancias y hondas diferencias entre los hombres.

En lo humano, entonces, le "toca a la prudencia precaverse" (Ibíd., p. 160) para tejer consecuentemente el relato de las circunstancias que le trazan al hombre una historia de connotaciones oscuras y fríamente planeadas en la intención de un poder que divide para reinar.

Por lo anterior, se torna imprescindible volver sobre el legado intelectual de Simón Bolívar, quien, como político y militar, contempló y actuó en unas circunstancias de una realidad continental determinada por "los sacrificios de la guerra" (Ibíd., p. 159). El Libertador advierte de la necesidad de comportarse ante el descalcificado cuadro social de su época, que no es distinto al de la actual, con "vigor y fuerza moral" (Ibíd., p. 159) a fin de no desatender el compromiso político de alcanzar "la igualdad legal" (Ibíd., p. 161), dentro de un humano intento por "corregir en cierto modo la injusticia de la naturaleza" (Ibíd., p. 161) en su versatilidad y particularidades físicas.

\section{Metodología}

Se propone una investigación documental cualitativa por cuanto se pretende hacer construcción de teoría alrededor de un personaje que no ha sido considerado un pensador en el orden de lo filosófico. Se emplea un enfoque sistémico, con la intención de abordar de manera detallada cada uno de los apartados que componen el cuerpo teórico. El método a emplearse 
será el hermenéutico para poner en diálogo cada uno de los discursos que serán apoyo a la consolidación de la hipótesis.

\section{Desarrollo del artículo}

La variedad de elementos que componen un sistema vital participan del complejo fenómeno de las alteraciones en una respuesta de lógico, pero tenso acontecer evolutivo. Las referencias objetivas y subjetivas que integran el conjunto del universo, presentan una inmediatez altamente arbitraria en su belleza y volcamiento; una gracia de caracterizaciones cercanas a lo perfecto, que recorre necesariamente, los escaños que aproximan a su imparable ruina.

Tras esta innegable e inmodificable condición cósmica, en la cual confluye la manifestación de los entes naturales y racionales, se anuncia la potencia circunstancial, donde cada hombre adopta para sí una historia, desde la cual se registra su experiencia de búsquedas y prácticas.

El hombre, inmerso y determinado por estas circunstancias, tiene que afrontar de manera inesquivable un acervo de contingencias que remiten al deber de la pregunta y a la actuación delimitada por unas condiciones específicas del medio. Esta confrontación del hombre con el ambiente que lo circunscribe, se escapa de toda prescripción racional que pretenda anticiparse a catalogar o manualizar la reacción de la materia, e incluso, sus propios atributos.

Ciertamente, el mundo no es un teatro, en el cual se recita el guión y se planean sus escenas; dista mucho de ser un catálogo o un manual que se archiva y se consulta para desempolvar sus diseños; es ante todo, un palpitar material que en cada pulsación expele una prolongación incierta de la vida; un ritmo esquivo de la matematización de su fuerza.

[...] Descartes medita, cree, pues, [...] que el mundo posee una estructura racional, es decir, que la realidad tiene una organización coincidente con la del intelecto humano, se entiende, con aquella forma del humano intelecto que es más pura: con la razón matemática (Ortega y Gasset, 1958, p. 9).

Pero, indudablemente, esta mediación fracasa, rompe los lazos de la deseada coherencia, o más aún, coincidencia, entre las planeaciones men- 
tales del hombre y el desarrollo de la materia; la promulgada realidad del hombre como un estado contemplativo de atribuciones internas no es más que una falacia desde la cual se pretende responsabilizar a cada individuo de su tragedia o de su júbilo, pretendiendo hacer ver de forma más general que todo hombre es dueño y medida de cuanto existe y acontece, cuando en esencia, éste es desde sus circunstancias, en el corazón vibrante de una realidad que lo cifra y lo signa.

Desde la perspectiva de cada vida individual aparece la creencia pública como si fuese una cosa física. La realidad, por decirlo así, tangible de la creencia colectiva no consiste en que yo o tú la aceptemos, sino, al contrario, es ella quien, con nuestro beneplácito o sin él, nos impone su realidad y nos obliga a contar con ella. (Ibíd., p. 13)

En este imperativo de circunstancialidad, la historia pasa a ser entendida como el acopio y registro de las situaciones humanas que son expresadas en aras de la comprensión, donde el pensamiento se compromete con una búsqueda permanentemente, renaciendo en sus intenciones de verdad.

De esta manera ver es precedente de verdad, y la verdad ha de ser anterior a la versión que retoma al hecho, al objeto, al fenómeno o la escena en un acto de traducción protagonizado por la palabra. Y aunque de manera apresurada se puede formular la antítesis de que no todo lo visto es verdadero, bastaría con hacer una diferenciación conceptual entre verdad y realidad para hallar una primera vinculación semántica entre verdad y certeza, por un lado, y realidad y relatividad, por el otro, en tanto lo percibido en la posibilidad de lo cognoscible tiene existencia, mientras que lo vivido tiene perspectiva.

Ahora bien, bajo la lección bíblica Quien tenga ojos que vea ha de entenderse que la verdad no es posible sin el esfuerzo que caracteriza el ser de lo finito y dialéctico; es menester despojarse de las vendas que se han sostenido en la ignorancia, romper con el empecinamiento de una tradición supersticiosa y resignada que se ha consagrado a omitir la lógica universal, las convulsiones del mundo y las contradicciones de la sociedad.

Y es sensato pensar que dicha omisión está asociada al temor de romper con una imagen que ha permanecido inmóvil, sin instigar a la mente a ocuparse de otras concepciones y riesgos, sin agobiar la conciencia, sin confrontar el entendimiento, sin convocar a la razón al amplio y complejo 
ámbito de los significantes que aún no han sido significados, pero no es justificable aceptar que la apuesta por "tomar decisiones y el ejercicio de la voluntad son muy fatigosos" (Russell, 1976, p. 169), cuando hay por delante toda una tarea histórica por emprender y cumplir, un deber ético y moral por desmitificar el mundo y las relaciones que en él se fraguan para imponer realidades, y en esa medida discursos absolutistas, ideologizantes y castrantes de la impostergable tarea transformadora del ser humano.

Ver para evidenciar a través de la fonética es una labor filosófica que tiene como propósito transportar la verdad como fenómeno en la representación lingüística, donde, al cumplir plenamente este objetivo el concepto resplandece al ente, pues él, como sonido, hace memoria del significante no constatable en la inmediatez de la presencia, pero sí constatable con la imagen mental que encaja con la enunciación.

En esta labor epistemológica la Lingüística cumple un papel revelador del mundo, permitiendo que los seres humanos se comprendan inmersos en un espacio moviéndose en relación con el tiempo y con las leyes cósmicas que son antesala de todo evento. Estos eventos al ser contados, divulgados en la coherencia teórica, aproximan a la predicación el contenido suficiente y necesario de la coseidad arrancada de su anonimato en el habla y testimoniada de su existencia en la escritura.

Sin embargo, en esta relación de conocimiento, la verdad no puede entenderse como una categoría inmóvil, en tanto ella es una respuesta derivada de la continuamente renovada dinámica del universo, lo cual indica que el vínculo entre lenguaje y epistemología es inclausurable, pero mediado por una indisoluble coherencia que favorece la narración del mundo: sus manifestaciones, cambios, relaciones, alteraciones y acomodamientos; una narración que no sería ética si desatendiera la ubicación y el desplazamiento del hombre en este ámbito, en el cual también construye condiciones de vida, y se instala o resiste a la cadena de pertenencia del mundo al cosmos, es decir, a la relación gramatical determinada por el principio del cambio, dentro de una dialéctica de leyes complementarias, orquestando la filigránica melodía de un cosmos asombrosamente estético y complejo.

No en vano, la verdad se deja acompañar por la existencia y la naturaleza del mismísimo "corazón del universo" (Bolívar, 1971, p. 122) que se anuncia a "todos los recintos de la tierra" (Ibíd., p. 123) para entregar "a la familia humana [...] los tesoros que abrigan sus montañas de plata y de oro 
[...] comunicando sus preciosos tesoros a los sabios" (Ibíd., p. 123) capaces de conducir esta información a virtuosos destinos; capaces de llevar estas directrices físicas a modelos éticos e históricos que comprometen a las sociedades con una réplica de acatamiento a las reglas universales que hacen de lo diverso un emblema de unidad.

Y será claro, en este recorrido que llega hasta el hombre como especie, un proceso humanizante que permita dirigir la voluntad y la inteligencia hacia la aprobación y reverencia de la vida, donde la libertad convoca a las actitudes y los comportamientos a formar parte de la reciprocidad y armonía del universo, asignándole a la palabra una responsabilidad que sobrepasa la cercanía con las cosas, en tanto las ve y las nombra. En la tarea humana, es la vivencia la que inspira el anunciado, y por ende, la capacidad de sentir más allá de lo que los sentidos permiten, pues se trata de percibir dentro de una relación política, que, en tanto ella misma, no es distante con el equilibrio de la naturaleza, en cuanto dicha diversidad converge en la armonía de ciclos y principios de respeto a la vida y particularidades de cada especie.

Sería pues, sentir la vivencia de mímesis de la verdad en la realidad social traduciendo belleza, verdad y bondad del universo, como justicia, libertad y dignidad entre los hombres; en suma, en la igualdad humana que es capaz de entender la diferencia del hombre, pero también su disposición y factibilidad hacia lo perfectible.

Sin embargo, la vivencia de la realidad ha sido relativa a la ubicación y experiencia del hombre en sus particularidades culturales, sociales, simbólicas, económicas, ambientales y políticas. Todo hombre define su realidad desde la individualidad de sus circunstancias; se instala en una minoría con la cual se identifica, y empieza a hacer de esa realidad un insumo de esfuerzos y búsquedas.

Pero es necesario que la concepción de realidad se funde en unos antecedentes históricos que tienen que ver directamente con la naturaleza política, es decir, con el vínculo entre los hombres en un territorio común; coincidencia que los une, además, en un conglomerado de pueblo que debe apelar a ciertas comprensiones comunes que favorezcan la cohesión y permanencia como patria.

Ahora bien, como parte de la conducta y actuación humanas en lo colectivo, se oficializan elementos o esquemas que empiezan a constituirse 
como rasgos preponderantes e identitarios de sus relaciones e interlocuciones; crean instancias de rigor en la confianza de preservar lo que consideran un bien compartido y conviven bajo el significado de la hermandad, dentro de un cuadro espontáneo de valores y creencias, pero con una jerarquía de respeto y reconocimiento de quienes pueden llegar a ser considerados como referente en su sabiduría y experiencia.

Al menos en el caso continental, éste puede ser considerado el preámbulo del ejercicio político, en el cual se comunicaban, compartían, comulgaban y convivían en sintonía con la naturaleza, desde el primitivo concepto y práctica de vida comunista.

Pero la avalancha eurocéntrica irrumpió en esta concepción y estilo de vida, importando una realidad, que hoy todavía, se sigue repitiendo en obediencia inescrupulosa a los mandamientos del capitalismo. Y es aquí, en este contexto de la más inaudita pérdida de valores, sobre todo de las minorías gobernantes, que son conducidas y que conducen en un sistema político amoral que convoca al consumismo, invirtiéndole a la ignorancia y sometiendo al pueblo a todas las más aberrantes condiciones de vida, cuando no de atropello, represión, señalamiento, persecución, destierro, desaparición, tortura y muerte, que se hace trascendente la responsabilidad política de la Lingüística, en tanto la realidad se presenta como un significante que comporta nuevos significados.

De manera obvia, la presencia del hombre en el universo, le suma a la fenomenología física y natural, situaciones sociales y humanas que se escapan de la consideración estética y ordenada de la naturaleza. El hombre es desaforado en su manifestación biológica, su instinto rompe cualquier justeza de pensamiento, palabra o acto; alimenta intenciones individualistas y arrolladoras, inviste de poder su búsqueda de bienestar y se amanguala en estrategias diseñadas por el mejor postor, y por consiguiente, por las más tentadoras promesas de reconocimiento, enriquecimiento y exceso.

Éste ha sido el lamentable desdibujamiento de la política, dentro de sistemas políticos sostenidos por la corrupción y la impunidad, por la mentira y el silencio ante ella. Es en este sentido que "las lecciones de la experiencia solo muestran grandes períodos de desastres, interrumpidos por relámpagos de ventura" (Bolívar, 1971, p. 128), tal como lo deja ver Von Humboldt en una melancólica reflexión que plantea claramente la diferencia entre la belleza y la bondad de la verdad como reflejo del orden de la 
naturaleza, y la descompensación y frustración moral por la incongruente realidad:

He vivido en un desierto moral. Los acontecimientos que acaban de destruir nuestra independencia política, y los que han preparado esta caída desastrosa, y que la hacían prever, todo me infunde la nostalgia de mis bosques del Orinoco y de la soledad de una naturaleza tan majestuosa como benéfica. Después de haber gozado de una dicha constante, que duró diez o doce años, y después de haber vagado en regiones lejanas, ¡he vuelto sólo para compartir las desdichas de mi patria! (Von Humboldt, 1991, p. XL)

Tanto la vida como la historia le guardan un destino al hombre, lo comprometen a desenmascararse de los falsos modelos de significación para asumir la realidad y los dictados desde donde se afrontan las circunstancias para elaborar verdaderas codificaciones semánticas.

En el tiempo de la vida y el espacio del mundo, se redacta el mandamiento de la humanización; se contempla la luz de la palabra que cuenta la naturaleza y la muestra en su orden, en su poética y en sus cambios. Ese brillo que en el pensamiento del Libertador invita a poner la mirada "delante de los cuadros de los colosos, de los tesoros, de los secretos, de los prodigios que encierra y abarca" (De Zubiría, 1983, p. 23) la naturaleza, convidando al profundo y ardoroso encuentro entre el pensamiento y la grandeza cósmica, entre la palabra y la fuerza poética que otorga contemplación y comprensión a la belleza geográfica.

Es menester, pues, salir de sí, abandonar el estrecho capullo de la alienante cotidianidad para percibir en ella una seducción liberadora que conduce a la cúspide de lo estético desde el labrado trágico de la vida que aspira leer y hacer suya la imagen serena y armónica del universo, tal como lo contemplara Von Humboldt en sus apasionados diálogos con la naturaleza: "Las noches son encantadoras; una pureza en la luz de la luna en estos cielos dulces y tranquilos, que me permitía leer las finas divisiones del sextante; y las constelaciones australes del Centauro y del Lobo" (Von Humboldt, 1991, p. XXV). En esta misma perspectiva, Bolívar se comunicó con la vida del paisaje geográfico, viendo en su estética una elevada significación de la dignidad apetecida por la masa humana. 
Ir al Chimborazo, profanar con la "planta atrevida la escala de los titanes, la corona de la tierra, la almena inexpugnable del Universo nuevo" (De Zubiría, 1983, p. 23) no es la estación azarosa de quien, en senderos indescifrables, se extravía en la asombrosa coincidencia de hallarse ante lo más cercano al paraíso; es la experiencia ineludible de quien se ha detenido a pensar la realidad y se ha dolido de las adversidades que en ella irrumpen como intención de desmedro y atropello de la dignidad humana, es inmiscuirse, como lo señala Röhl (1991) en homenaje a la labor de Von Humboldt, en "una descripción tan brillante de su naturaleza" (XXVI), en la cual con "delirio contemplaba la soberbia naturaleza tropical" (XXVII).

El acontecer dialéctico de la naturaleza juega en la armonía que es sucesión de opuestos; pero en la dialéctica del poder, lo antagónico es esencialmente lo contrario. De ahí que el poder ajeno a la naturaleza, a sus ritmos y variaciones, constituye el detonante de adversidades, que tampoco tienen punto de convergencia con el peligro de la circunstancialidad existencial, es ante todo, la intencionalidad utilitarista que no está conforme con el sentido de la justicia social, de la libertad y la paz; es la exaltación del egoísmo, como actitud contraria a las leyes de la naturaleza, en su actuar de complementariedad y equilibrio, donde se ven "florecer las artes de la paz" (Von Humboldt, 1991, p. L).

Entender la armonía interna de la naturaleza, es aceptarla como espejo y molde de la enunciación, reconociendo que todas sus manifestaciones son igualmente un evento axiológico que contribuye a la estrecha relación entre conocimiento y virtud, pues en la convicción de que la naturaleza deja leer la verdad en la extensión de su complejidad, habrá que respaldar dicha lectura con la honradez de la divulgación que torna todo conocimiento como un patrimonio al que la humanidad recurre para mejorar su estar y participar en y con la naturaleza.

Sin embargo, dentro de todo este caminar en alerta con el mundo, es también principio de honestidad el reconocer la limitación del hombre como un andamio más en el destino que traza una vida auténtica. "Todo lo que somos positivamente lo somos gracias a alguna limitación. Y este ser limitados, este ser mancos, es lo que se llama destino, vida. Lo que nos falta y nos oprime es lo que nos constituye y nos sostiene" (Ortega y Gasset, 1994, p. 68), lo que impulsa y posibilita la persistencia en una montaña de convicciones que van tras lo ausente, en aras de la construcción de alter- 
nativas o cambios que invierten la opresión en libertad, en un hacer que también es unidad.

"Todo vivir, individual o colectivo, es un hacer; más precisamente, un hacerse. [...] Y si la conciencia no anda turbia, vemos con indomable evidencia el plano de esa tarea y en él el lugar y la porción de esfuerzo que nos corresponde" (Ibíd., p. 72), la intención y disciplina de entrega que eleva la moral como "el ser mismo del hombre cuando está en su propio quicio y vital eficiencia" (Ibíd., p. 72); cuando está observando, "el cielo y la tierra, admirando el pasmo de la creación terrena" (De Zubiría, 1983, p. 23), preguntando "su edad, su vida y su esencia primitivas" (Ibíd., p. 23); preguntando también el lugar de quien interroga, para que su respuesta en el diálogo con la naturaleza no desflore "sus divinos atractivos, sus gracias maravillosas, sus virtudes intactas" (Ibíd., p. 23), ya que "el trono de la naturaleza [...] será tan duradero, indestructible y eterno" (Ibíd., p. 23) como pulcra, consciente y honesta sea la mirada y el tratamiento de quien se asombra y se descubre en sus profundas y extensas páginas de revelaciones.

La moral "es simplemente el ser inexorable de cada hombre, de cada pueblo" (Ortega y Gasset, 1994, p. 73), es la posibilidad de ser él mismo, en autenticidad y fecundidad de su historia, en reciprocidad con la naturaleza, con sus elementos, sumiéndose "en el duro quehacer propuesto por su individual destino" (Ibíd., p. 73), que es la forma más honesta de estar y permanecer en un continuo renacer, en el cual "la vida no es solo nuestro 'yo', sino que es también el mundo en que ese yo tiene que realizarse" (Ibíd., p. 78), un espacio abierto que no solo se expone para ser descubierto, sino también transformado, asumido desde el cristal filosófico que pone de relieve las formas y los contenidos que conviven como sustancias cósmicas, pero igualmente como adiciones humanas, con lo cual el mundo no es solamente un devenir en sucesión de eventos en íntegra y compleja gramática de revelaciones, sino también, una construcción del hombre que, aunque muchas veces participa del orden propuesto por la exterioridad, muchas otras, altera y contradice su armonía.

Mirar y sensibilizarse ante esta urdimbre es aceptar que "la vida es siempre drama" (Ibíd., p. 78) digno de padecerse al afrontar el destino, es decir, al ser capaces de permanecer en el "verdadero ser" (Ibíd., p. 79) en integridad con un mundo que reclama ser dicho en la verdad y pensado a la luz de los fenómenos que pone en evidencia. "Toda verdad del hablar supo- 
ne la verdad del pensar. Pero no hay verdad en nuestro pensar si no hay una verdad anterior a uno, la verdad de ser, de ser el que auténticamente se es. Y, quien miente en su mismo ser sólo puede sostenerse en la existencia fingiendo un universo falso" (Ibíd., p. 79), negando el orden de la naturaleza y la contaminación de su suelo, negando "la filosofía como conocimiento del universo [...] que es un objeto integral [...] el auténtico todo" (Ibíd., pp. 106-107) que ha de ser buscado, preguntado y moldeado.

Pero es en la vida misma donde se encuentran las rutas, las montañas y los paisajes que levantan ideas y convicciones para impulsar los actos. El universo es un orden que lleva sobre sí la complejidad de la vida, esa "selva salvaje" (Ibíd., p. 321) donde cada hombre encuentra las señales de su destino y lee los párrafos de su historia; "trabaja por encontrar en la selva "vías", "caminos"; es decir, ideas claras y firmes sobre el Universo, convicciones positivas sobre lo que son las cosas y el mundo" (Ibíd., p. 321), sobre lo que es el hombre dentro de esa realidad que lo determina, pero a la cual también puede alterar para adaptarla y adaptarse en una relación de comprensión, que presupone además, disyuntiva y transformación.

Efectivamente, la relación entre el hombre y el mundo está supeditada a las fricciones, ya que ambas realidades, la humana y la cósmica, aunque convergen en la unidad simbólica por antonomasia, la cultura, corresponden a propósitos bien diferenciados. En la naturaleza todo acontece de manera desinteresada, en una armonía propia que plantea unas leyes físicas y filosóficas de orden y complejidad inherentes al dialéctico devenir de la consecución y la correspondencia; mientras que en el hombre puede haber una intencionalidad, un destino, una meta que ayuda a superar los embates de la vida.

De esta manera la mente se apropia de un conjunto de significados para configurar el ambiente cultural como experiencia de construcción existencial que "salva del naufragio vital" (Ibíd., p. 321), dotando cada momento histórico de razón de lucha, esfuerzo y dedicación; puliendo así mismo cada una de las valoraciones que se tienen del mundo, en su movimiento y multiplicidad, construyendo "una idea del espacio y del tiempo en que se vive" (Ibíd., p. 324). Y, aunque "la misión de la idea es reflejar la realidad" (Ibíd., p. 497), hay ideas que tienen como misión promover nuevas realidades, en las cuales la relación del hombre con el mundo no esté cifrada por posiciones de poder, y por ende, por ambiciones minoritarias que definen poderosos y oprimidos. 
Se trata, pues, de unificarse dentro de un punto de equilibrio, en el cual la convicción del hombre no sea ajena a la equidad de la naturaleza, que, sin excesos ni mezquindades participa de un solo pulso de vida: en el solidario y fluido movimiento de ser y realizarse dentro de la unidad más diversa: el universo.

Ahora bien, es claro que tal estética de diversidad, no puede ser solamente un fenómeno que se mira dentro de la plástica semántica que permite recrear con palabras el afuera, es menester construir la vitalidad conceptual en sintonía directa con el sentir y pertenecer a un territorio, a una concepción de tierra, desde la cual no solamente hay un giro de comunión con el tiempo, sino también una pausa de identidad, que no tiene simplemente que ver con el nombre, sino, y más aún, con la pertenencia, es decir, con la voluntad férrea de hacer en el sentido de la cultura, como patrimonio inviolable del ser y el estar con otros.

Este otro nivel de interacción implica, de antemano, el límite, pero no como obstrucción de búsqueda, sino como reconocimiento de que la aprehensión de la realidad constituye el ámbito de experiencia con una fracción del mundo, en la cual está representada la cobertura cognoscitiva en el plano de la relación entre el hombre y la exterioridad, mediada por la actividad práctica como propósito fundamental del conocimiento en su auspicio a la comprensión y transformación. De ahí que la vida sea, en un alto componente, sentido biográfico, que corresponde al "conjunto de lo que hacemos y somos [...] entre las cosas y seres del mundo. "Vivir es, de cierto, tratar con el mundo, dirigirse a él, actuar en él, ocuparse de él" (Ibíd., p. 341) en el día a día de la experiencia de contemplarlo, sentirlo y padecerlo en ese contexto vital que es la Tierra.

En este sentido el acopio de convicciones que permiten estar y acercar al mundo, es recibido del "medio histórico" (Ibíd., p. 342), como interpretación canalizada, resguardada y renovada en la cultura, es decir, en el cultivo de esa porción de tierra que permite ver "a plena luz los caminos de la vida" (Ibíd., p. 344), que aprueba escuchar las deidades del tiempo transitando la eternidad para mortalizar su palabra, es decir, hacerla dominio humano en "la superioridad de la fuerza moral" (Bolívar, 1971, p. 54) capaz de "romper las cadenas de aquellas víctimas que gimen en las mazmorras" (Ibíd., p. 57) esclavizadas por la opresión, la ignorancia y la desmedida. 
Es en este compromiso histórico y moral, donde la verdad "se dirige a romper las cadenas de la servidumbre" (De Zubiría, 1983, p. 66) para concebir y encontrar "la senda de la justicia" (Ibíd., p. 67), se vence "la ceguedad e ignorancia" (Ibíd., p. 67) que es precedente de todo crimen y mancha de toda obra. La cercanía con el mundo, apremia de limpieza en la conciencia, pues así el conocimiento podrá llegar a ser un testamento y testimonio de la lucha del hombre por vivir digna y auténticamente.

Toda calamidad, desventura y tragedia que en su magnitud y significado logre hasta "estremecer a la naturaleza" (Ibíd., p. 70) tendrá que ser mirada y afrontada como contraria a la lógica de la unidad axiológica entre el mundo y el hombre, ya que en dicha asociación median sentimientos y valores donde el tiempo empieza a ser una constelación compartida desde la memoria, la historia, los esfuerzos y los destinos comunes; es decir, la unidad social, en la cual se propende por vivir en una melodía de estrofas colectivas, entre estruendos y silencios que recogen el mismo sentir y el mismo avanzar. Y bajo este ritmo es que la verdad del cosmos se encarna en el compromiso ético que afronta la realidad desmantelando las maquinaciones, manipulaciones y extravagancias encaminadas a separar el significado de armonía de las significaciones de la realidad, lo cual significa apartar al ser humano de su derecho al bienestar integral.

Para este momento gramatical, se eleva el significado a la expresión de construcción, es decir, a un ejercicio semántico tejido en la intencionalidad cognitiva que fecunda la razón en pensamiento, y este, en palabra donde reverdece el mundo, donde se hace, ya no exclusivamente exposición fenomenológica, sino, fuerza imaginativa, en la cual las ideas no solamente son imagen fonética, sino narración anticipada que anuncia un destino.

Pero no es lícito anunciar un destino sin la consideración objetiva de espacio, es decir, de extensión geográfica que recoge en su orden de infinita variedad de presentaciones, un lugar común de origen histórico al cual ingresa el hombre como un cultivador de ideas, como un artesano de creencias y como un artista que representa su centro vital.

El lenguaje pasa así a ser el túnel simbólico que transporta el eco de ese primer esfuerzo humanizante que configura la expresión colectiva creadora de cotidianidad en un territorio que anuncia la actuación real de la cultura sobre el suelo de identidad del que emerge el pueblo como un 
cuerpo retornando a la memoria de un mismo pasado, permitiendo además que los recuerdos permanezcan en diálogo con los sentidos y metáforas que labraron un presente, con los dolores y decisiones que esculpieron un camino para asumir el devenir en referente histórico ineludible por la piedra neural de la memoria. "En cada pasado se proyectó un futuro" (Roig, 1984, p. 3) que no puede ser abandonado por el pensamiento en su tarea de hacer y reflejar el lenguaje que contiene en sí la imagen compartida y construida del mundo como fracción vital, en suma, como porción identitaria de un pueblo que con sus símbolos, consignas, cantos, ideales y convicciones siembra y recoge su definición de tierra.

Y es básicamente sobre este criterio que la concepción de orden en el universo se transcribe desde la apropiación de una experiencia que es metáfora, reflejando el encuentro entre la naturaleza y el hombre, donde el asentamiento histórico conduce a necesidades prospectivas que develen los encubrimientos políticos y económicos que no han permitido relaciones nítidas a nivel cultural y social.

Así, pues, y sin mancillamiento de una semántica que haga corresponder al hombre con su realidad cósmica, se hace imperante la reconciliación entre un espacio con situaciones y objetos concretos, y una dialéctica con miramientos de lo posible, sustentada en la unidad popular organizada que no le atiende a la inescrupulosa y arbitraria distancia que los intereses de la ignorancia han creado con la utopía, ya que ella, ciertamente, "es lo que puede no ser, pero también lo que puede ser o que, por lo menos, nos aproxima a lo que puede ser. Diríamos que el peso semántico de lo posible queda expresado en el concepto de 'lo no-necesariamente imposible' " (Ibíd., p. 7), es decir, aquello que aún no ha sido explorado en sus posibilidades por la ciega obediencia a su manipulada connotación.

Aludir a lo posible en función de lo imposible, es darle ya a este último un fundamento dialéctico que tiene implicaciones directas en el ser y el hacer del hombre, de tal forma que la existencia esté sustentada en el hecho mismo de formular y replantear continuamente nuevas avanzadas que actualizan y nutren el sentido del destino.

Es además razón sustancial afrontar esta inminencia del cambio en la integralidad del encuentro que constituye el mundo como verdad cósmica, en cuya lógica asombra la estética, pero también del encuentro que signa la experiencia con el mundo en su expresión de realidad, donde es justamente 
lo social el contenido fluctuante de manifestaciones en significados de exceso, desproporción y disyuntiva.

El conflicto inherente a la sociedad de clases deja al descubierto este panorama de fractura, o más aún, de tensión continua entre las partes que integran el desarrollo de la sociedad y del pensamiento, desde las leyes del cambio que presuponen fuerzas opuestas en actuación, pero en afinidad con una concepción de separación que traza distancias históricas, coyuntural u organizativamente puestas en equilibrio en la confrontación física, que es a su vez, la arremetida frontal por invertir posiciones. Pero en dicha mudanza, la clase sometida, es decir, el pueblo, no transita los mismos móviles y significados de la clase dominante, puesto que al apelar a la violencia como vía de emancipación, instaura el tránsito a un orden de igualdad y desarrollo social que propende por la superación de la situación de explotados y excluidos.

En efecto, uno de los párrafos que pasan sobre la textura de la tierra es el de la violencia, la cual, como lo expresa Guzmán (1980):

[no se] ha sopesado en toda su brutalidad aberrante, ni tiene indicios de su efecto disolvente sobre las estructuras, ni de su etiología, ni de su incidencia en la práctica social, ni de su significado como fenómeno y mucho menos de su trascendencia en la psicología del conglomerado campesino; ni de las tensiones que creó, ni de la crisis moral que presupone, ni del enjuiciamiento que implica a los dirigentes de todo orden, ni del llamado que formula a una permanente, eficaz y serena meditación del problema que plantea (Guzmán, Fals \& Umaña, p. 23).

Con la violencia, la fraternidad y la armonía de la geografía en su compuesto de ríos y montes, con su limpieza y exuberancia estética, pasó a ser, tal como lo dejara ver Monseñor Builes, citado por Guzmán a propósito de la cruenta época de 1954-1956 en Colombia, "El infierno en la tierra" (Ibíd., p. 113), "decenas y centenares de niños, ancianos y gentes humildes muertos por las bombas, asesinados en sus casas por las fuerzas oficiales o acribillados por el hambre y las enfermedades" (Ibíd., p. 108). Terrible telón que ocultaba la belleza de un suelo fértil y generoso con sus gentes, ensombrecía el sentido de la vida y tornaba lúgubre todo amanecer, que antaño era recibido por la alegría del sembrado, el riego, la recolección y el alimento. 
Preguntarse por las razones de estos fenómenos no es menos importante que preguntarse por el universo en su orden; es más, la discrepancia entre las manifestaciones de origen natural y las de origen social deben agudizar la atención dentro de un claro compromiso lingüístico y ético que no deje en la impunidad las descarnadas escenas y consecuencias de la violencia, que han obligado a que la misma belleza de la geografía se convierta en cómplice de nuevas formas de accionar popular.

El miedo por el ataque a la vida redime otros sentimientos por su misma defensa, y si en un momento la respuesta es huir y lamentarse por la inclemencia de la desigualdad y el abuso, los desollamientos continuos sobre las mismas heridas, convierten a la naturaleza en hogar de alivio, pero también de preparación a otras respuestas: "emigrar a los montes" (Ibíd., p. 107), "refugiarse en las montañas y selvas" (Ibíd., p. 108) es la única alternativa ante el ataque inverosímil de hombres ignorantes e incapaces de desobedecer órdenes que matan su propio origen. Los montes, montañas y selvas se traducen en la geografía de la unidad que mantiene en alto el deseo históricamente humano de "Paz, justicia y libertad" (Ibíd., p. 109) que tan manoseado ha sido por la vil demagogia oficialista que ha dejado al pueblo en una fotografía que hace réplica de las palabras del economista Antonio García, citado por Guzmán,

[...] en ese subsuelo anónimo, invisible a los ojos, fuera de todo horizonte político. Nadie ha querido verlo: los republicanos de todos los partidos han hablado de su soberanía y han escarnecido su incapacidad de moldear y conducir su propia suerte. Le han movilizado para las guerras electorales o para las guerras civiles y le han dejado ahí, al margen de la historia, aislado de una patria que no está presente en sus necesidades, en sus problemas, en su drama biológico y espiritual. (Ibíd., p. 114)

Pero esta pesadumbre no es el agüero que pesa en el imaginario interno de una sociedad signada por una confrontación interna, propia de la algidez de la oposición clasista; es legendaria la marca siniestra de esta ley del desarrollo social, que en las pulcras y comprometidas palabras del Libertador registran así el auxilio en la naturaleza: 
[...] todos vacilaban, hasta que asegurados de tan calumniosa felonía, huyeron a los montes a buscar seguridad entre las fieras, dejando desiertas las ciudades y pueblos, en cuyas calles y caminos públicos no se veían sino europeos y canarios cargados de pistolas, sables $\mathrm{y}$ trabucos echando fieros, vomitando venganzas: haciendo ultrajes; sin distinción de sexos, y cometiendo los más descarados robos (Bolívar, 1978, p. 251).

Y si la pregunta se dirige a la verdad de este derrumbamiento, la primera y única vía conduce a señalar a los responsables, quienes no solamente cargan la culpa de su imposibilidad moral de asumirse y actuar como parte del equilibrio cósmico, sino de continuar efectuando, mediante acomodamientos discursivos y pactos de poder, estrategias de ataque, tortura, masacre y mutilación de opciones que permitan la emancipación de esta oscura noche. Pero en medio de la poca luz posible, es obligación volver sobre las palabras de García, insistidas por Guzmán, para no perder claridad en este deber histórico: "Los verdaderos responsables de este derrumbamiento no son los delincuentes vulgares: es el sistema político que los toma como sus instrumentos, como sus órganos de dominio, que los alienta, que los estimula, que los remunera, que los premia" (Ibíd., p. 114), que los embrutece en el ruido bélico del falso heroísmo que continúa "cosechando la única siembra que han hecho nuestros partidos históricos: en esta sangre derramada, en estos delitos infamantes, en esta crueldad sin castigo, se resume el sentido de nuestra historia partidista" (Ibíd., p. 114).

Empero, no tendría ningún mérito en auscultar para poner en evidencia algo que durante tantas décadas se ha contado solo, se ha dicho en su intencionalidad, y de hecho, se ha materializado como sombra de una cotidianidad que parece ser aceptada. En este ir por el mundo de la vida que se mueve hasta en los más inimaginables confines del universo, el papel del hombre no puede reducirse al del turista que exclama admiración y abnegación por el sublime atardecer que sucumbe a la extensión de la noche. Tal tendido de oscuridad no puede remitir a la comodidad del descanso, del sosiego y la indiferencia pues, otra vez en las palabras de García retomadas por Guzmán, "Todos estamos viviendo — conformes, cristianos, fríos, monstruosamente tranquilos- sobre esta herencia de sangre" (Ibíd., p. 114). 
Todos, aunque no responsables de las razones que originaron tal magnitud del conflicto, hemos cotejado y reproducido el proceder de quienes robustecen "esta degradación multitudinaria [...] esta renovada mutilación de todos los hombres humildes" (Ibíd., p. 114), quienes, por si no fuera poco con padecer como víctimas directas las atrocidades de la violencia, encuentran en "los intelectuales, las élites, los grupos dirigentes" (Ibíd., p. 114) una tolerante actitud frente al crimen que los hace también responsables "por su cobardía, por su egoísmo, por su estrechez moral, por su noción deforme de la patria" (Ibíd., p. 114), encasillada en una percepción pro establecimiento que no se inmuta en divulgar "los más horrendos asesinatos, robos, violencias y devastaciones" (Bolívar, 1978, p. 250) donde coincidencialmente, son "los pacíficos labradores, hombres más honrados, los inocentes [quienes] morían a pistoletazos y sablazos, o eran azotados bárbaramente" (Ibíd., p. 250).

Atreverse a una mirada comprometida de la realidad, supone entonces dejarse conducir en la luz del descubrimiento de sus implicaciones, en el sacar de la oscuridad la densa significación tejida por el particular significante de lo real hecho vida, o más aún, experiencia de padecimiento, impotencia e incertidumbre ante el deshonroso cuadro de saber a los hombres "arrancados del seno de sus mujeres, hijos y familias en el silencio de la noche: atados a las colas de los caballos [...]: conducidos con ignominia a las cárceles: [...] entregados a la inhumana vigilancia de hombres feroces" (Ibíd., p. 251).

Definitivamente, excluir la cuota de culpa por la indiferencia o ignorancia, no es solamente un reconocimiento de amoral proceder, sino una desfachatez discursiva que desconoce "la naturaleza de la historia como 'tarea'" (Roig, 1984, p. 3), como propósito creador de nuevas condiciones y nuevos hombres, como meta artesanal en la obra reivindicativa de la verdad, y por consiguiente, de la existencia que es coherente con "las formalidades más esenciales requeridas por la naturaleza" (Ibíd., p. 253).

Pero en este atrevimiento, que es además un deber, se dan los pasos hacia "un saber abierto" (Ibíd., p. 4), hacia una "filosofía para adelante" (Ibíd., p. 4) que no escatima el contenido de la realidad pero tampoco frena el ascenso estético de la belleza, la verdad, la libertad, la justicia y la paz, como principios "de un mundo de lo posible" (Ibíd., p. 10). Es, pues, el atreverse a la acción lo que resignifica dialécticamente al hombre para asumirlo como un ser humano en un ambiente real de historia y lucha. 
Este deber traza una misión moral y política, donde la palabra no es extraña al hecho, no es un sonido de lo inexistente, y por ende, un eco resoplando intereses de opresión y miseria. Una palabra recogida del compromiso libertario que enuncia "una integración dialéctica" (Ibíd., p. 10) en la reciprocidad moral y política sobre la cual se fragua "el modo de ser plenamente histórico de un hombre nuevo" (Ibíd., p. 10), no puede renunciar a los elementos que anteceden el hecho mismo de la enunciación; no le estará permitido desvincularse de las formas y sus fondos reales, a partir de los cuales la humanidad es movida y dirigida por los senderos de la esclavización y la ignorancia; no podrá desatender el palpitar de un pensamiento, liberándose de la opresión e incitando a la razón histórica a relacionar y divulgar las ideas que expresan el orden de un centro de encadenamiento mundial conocido y padecido como capitalismo.

$\mathrm{Si}$ "los profesores burgueses, pagados para embellecer la esclavitud capitalista," (Lenin, 1917, p. 6) lograran intuir el impresionante impacto de la verdad, como hermana del conocimiento que atiende a la sociedad y a las relaciones que se dan en ella, sería predecible concebir la posibilidad cierta de un hombre nuevo que rompa con el parasitismo y la descomposición que el imperialismo alimenta para llevar a su fase más elevada al capitalismo. De tal manera que el renacer a la condición verdaderamente humana, implique, de tajo y de fondo, conocer las columnas que sostienen el escenario y el ambiente de la desigualdad, la esclavitud y la amoralidad, para diseñar y ejecutar de manera contundente, acciones que derriben las bases de ese siniestro rompecabezas de manipulación y sometimiento.

Una nueva "historia de las ideas en la reconstrucción" (Roig, 1984, p. 11) de la dignidad arrebatada y el desmedro de la concentración capitalista, presupone "un claro matiz antropológico" (Ibíd., p. 11) que no sea mezquino con la consideración de sí mismo y del otro, es decir, que cuente con la certeza de ser y hacer parte de una realidad, en la cual incide toda conducta y actuación, en tanto son ellas la expresión de pertenencia a un laberinto simbólico que siempre exige nuevas perspectivas de atisbo ante la historia como resultado del quehacer continuo, ya que la vida es "pura tarea e inexorable quehacer" (Ortega y Gasset, 1965, p. 45).

En el hacer reposa la historia, pues es allí donde está la hondura del significado que convoca a la conversión del hombre, a su consciente humanización histórica, a la luz de un ideario axiológico que reaccione "ante la 
estrangulación por los monopolistas de todos aquellos que no se someten al monopolio, a su yugo, a su arbitrariedad" (Lenin, 1917, p. 23), que no se someten a la definición de una historia anclada en "relaciones de dominación" (Ibíd., p. 24). Un "sujeto de las ideas" (Roig, 1984, p. 11) que sea consecuente con su deber histórico, que no claudique en la intransferible tarea de mostrar y anunciar la verdad, que no limite su esfuerzo al cumplimiento de una voluntad egoísta y encasillante, que no se niegue a continuar intentando vías de lucha y emancipación, que no postergue su palabra y su acción para momentos menos inclementes, que no mutile su compromiso por vanidades y aspiraciones fútiles, que no ensombrezca su ímpetu fraternal por señalamientos y rumores. Un sujeto coherente, leal, disciplinado, solidario, honesto, valiente y amoroso; insobornable e intransigente con la traición, la mentira y la tiranía; que enfrente con radicalidad y entereza a todo aquello o aquel que tenga en su discurso y comportamiento "la tendencia a velar el fondo de las cosas, a ocultar el bosque tras los árboles" (Lenin, 1917, p. 33); un sujeto capaz de comprender que "para ser hay que actuar" (Ortega y Gasset, 1965, p. 46), en el legítimo derecho a componer la verdad, y las piezas sueltas de esta realidad tecnocrática y opresora.

Ante la imagen de este nuevo hombre puede augurarse el quebrantamiento de los estatutos de amoralidad antropológica que han reemplazado todo valor por el dinero, que le han puesto precio a los propósitos de los hombres, que han financiado la muerte poniéndole plazo a la vida, que le han otorgado crédito a la ignorancia prolongando el hambre y la miseria, “que disimulan y embellecen el 'mecanismo' de la formación de las oligarquías" (Lenin, 1917, p. 45), pregonando los dogmas del sistema, y robusteciéndolos en sus oportunistas lugares de favorecidos.

Y de este quebrantamiento, el paso a "la praxis liberadora" (Roig, 1484, p. 12) constituye el trascendente impulso moral intolerante con la "saña envenenada" (Bolívar, 1971, p. 66) que devora en su ambición y avaricia, irreversible en su actitud de resistencia y combatividad contra la intencionalidad prepotente de los enriquecidos en reivindicación del despojo y la explotación que pactan y conspiran "en la lucha rabiosa por alcanzar las últimas porciones del mundo todavía no repartidas o por conseguir un nuevo reparto de la ya repartida" (Lenin,1917, p. 83).

Es, pues, un deber moral conforme con las leyes del universo, en tanto convoca a saberse y sentirse parte del fenómeno social sin nacionali- 
dad ni reglas; que va contra toda lógica existencial, en desacato y desmedro de todo principio de unidad y armonía; un deber humano comparado con la ontología de la verdad, la belleza, la felicidad y la bondad, y que supone además el cultivo de "almas generosas" (De Zubiría, 1983, p. 68) que siempre "se interesan en la suerte de un pueblo que se esmera por recobrar los derechos con que el Creador y la naturaleza lo han dotado" (Ibíd., p. 68); esos derechos que permiten "elevarnos al goce de la libertad" (Ibíd., p. 70) "sobre las bases de la justicia, de la libertad y de la igualdad" (Ibíd., p. 76), únicos, verdaderos y suficientes cimientos para curar "las llagas y las heridas del despotismo y la guerra" (Ibíd., p. 76).

A la luz de este criterio es anunciada la virtud como un logro emancipatorio que abandona las tinieblas y sus gruesas cadenas de ignorancia para prepararse a las bondades de la felicidad, que en sí misma "consiste en la práctica de la virtud" (Ibíd., p. 97), es decir, en "el ejercicio de la justicia" (Ibíd., p. 98) que representa a su vez, "el ejercicio de la libertad" (Ibíd., p. 98) y por ende, la pertenencia a la "naturaleza a la verdad" (Ibíd., p. 98), en cuyo fondo reposa el significado de integración al cosmos en el sublime movimiento del ser siendo y haciéndose continuamente.

El ser es existencia en innegable dialéctica con la vida; participa del universo en idéntica relación de parte y totalidad, es decir, se referencia como fragmento que en sí mismo da cuenta del complejo y lógico estatuto cósmico, en el cual confluyen y actúan todos los elementos de lo macro particularizados en cada componente de la gramática y semántica universal.

Es en este ritmo de cambio y reubicación, donde acontece una nueva consideración de lo evolutivo, un nuevo campo epistemológico que percibe las transformaciones como consecuentes de las decisiones y elecciones tomadas y depuradas en la esencia de la libertad.

Ahora bien, tomar la libertad como principio de los eventos y los actos de evolución, presupone su comprensión dentro de una tensión dialéctica que sitúa el "goce pleno y absoluto" (Ibíd., p. 102) de su naturaleza "hacia la perfección social, que es fin único de las instituciones humanas" (Ibíd., p. 102); el lugar supremo de todo proceder moral que aspira a convertirse en imperativo categórico, aunque sin desconocer que no "todos los ojos son capaces de soportar la luz celestial de la perfección” (Ibíd., p. 103), pues la disposición o intención a la verdad, compromete con ser "intérprete de la naturaleza" (Ibíd., p. 103) o de todo aquello que acontezca en el 
ámbito de la Física, la Historia, las relaciones sociales, epistemológicas, tecnológicas, organizativas, en fin, en la construcción y producción de conocimientos que conduzcan a respuestas, en aras de la transformación y comprensión del hombre dentro de la sociedad.

Pero en esta proyección de integridad es imprescindible "practicar la virtud" (Ibíd., p. 104) para cumplir "con la justicia, con la humanidad" (Ibíd., p. 104), trascendiendo al más incuestionable compromiso virtuoso "con la política, con la sociedad" (Ibíd., p. 104), con la obligación histórica de frenar "el reparto del mundo y la explotación" (Lenin, 1917, p. 104).

En este grado de humanización la igualdad se entiende como intrínseca a la existencia y acusa "la ingratitud, el egoísmo, la frialdad del amor a la patria, el ocio, la negligencia de los ciudadanos" (Ibíd., p. 117); la indiferencia o el acomodamiento que se enclaustra en las sombras de la ignorancia, creyendo y promoviendo una sociedad ficticia, adornada por la mentira y los intereses de clase.

Entender este fenómeno y encararlo, implica descomponer la historia y sentirse parte de ella, desarmarla para descubrirla dentro de un mundo que "se presenta desde luego como primera materia y como posible máquina" (Ortega y Gasset, 1965, p. 46); un mundo que es a priori de la existencia, y que seduce desde las dificultades y circunstancias donde "el hombre se resuelve a buscar" [...] para sacar a la luz, para descubrir esa posibilidad de máquina que el mundo lleva latente en su materia" (Ibíd., p. 46) y que permite que "- - el hombre y el mundo - se vean obligados a unificarse, de modo que uno de ellos, el hombre, logre insertar su ser intramundano en el otro, que es precisamente el mundo" (Ibíd., p. 48).

Se trata entonces de ser creando, de ser en la existencia dentro de la verdadera lógica de la acción, que no se conforma con percibir para recibir y trasmitir unos códigos y normatividades supeditadas a moldes de coacción y estigma. Es la dinámica que adopta la vida desde estructuras de regulación y control, que se abre el debate frente al acierto o desacierto de dicha realidad.

No es, pues, una imposición que el hombre deba aceptar, es un intento por hacer ver la verdad como algo oscuro, relativo y subjetivo, para lograr diluir y dispersar a la humanidad en unos terrenos hostiles donde él se entiende en la manipulación sofística que le concede la potestad de ser la medida de todas las cosas. Si la naturaleza no es tal termómetro e incluso 
la textura sobre la cual el proceder humano se replica, no podría formarse el equivalente entre mundo y hombre a la luz de la gramática que antecede actos semánticos de verdadero contenido ético.

Podría afirmarse así, a modo de conclusión, que Mi delirio sobre el Chimborazo (1823), como evento natural frente al cual el Libertador se sumerge en la revelación onírica para despertar en el compromiso de buscar la verdad con los hombres, es el cuadro conceptual, donde el pensamiento transita el universo con el báculo de la Filosofía, o lo que es igual, con el tacto en la vida, en la experiencia, en las decisiones y acciones que permiten mutar en el devenir histórico. La mirada de Bolívar ante el Chimborazo expresa el compromiso humano que "dibuja" (Ibíd., p. 406), grafica con las palabras la verdad física y moral que define la relación entre el hombre y su entorno.

Toca así la palabra el corredor dialéctico, por donde han sido, son y se rehacen el mundo y la sociedad, por donde la mirada se asombra y se detiene para que el pensamiento fluya en el lenguaje, conquistando la versión que da cuenta de un momento de la verdad.

En esta conquista que ya ha reemplazado la superstición con la razón, y la metafísica con la existencia, el Libertador encarna la fertilidad de la metáfora; se deja poseer por la majestuosidad del paisaje y por la nominación divina de su perfección; descubre el mensaje de las páginas de la naturaleza en una semántica que es la "señal del paso de la esfera divina a la humana" (Ibíd., p. 46), pues si bien lo divino nombra para que el ente acontezca, es en el ente donde lo humano hace palabra, donde encuentra la verdad y la dice "a los hombres" (Bolívar, 1978, p. 406).

Entonces, son los ríos, el monte, las marcas geográficas, los confines del universo, la acumulación glacial, la textura de la Tierra, "el espacio que encierra la materia" (Ibíd., p. 406), el que alimenta conceptualmente la capacidad de habla, y el que conduce los significados por el camino de la comprensión, en tanto cada predicación es el reflejo de los "cristales eternos que circuyen el Chimborazo" (Ibíd., p. 406), de las lentes que posicionan la mirada a la conquista de la verdad.

Así, la gramática en la naturaleza es una experiencia fecunda para enriquecer el lenguaje, en tanto lo dispone a la enunciación que ve antes de emitir, y por tanto, que se allega a comprenderse como sustancia humana y humanizante en la medida en que relaciona al hombre con las cosas 
para permitirle un conocimiento hondo y amplio de su naturaleza: "Uno no puede conocerse a sí mismo como es debido más que a condición de tener sobre la naturaleza un punto de vista, un conocimiento, un saber amplio y detallado [...]" (Foucault, 1994, p. 83).

Conocer es elevar la mente hacia el acercamiento del mundo, que representa a su vez, el acercamiento al mismo hombre, a su naturaleza y esencia: el lenguaje, el cual, siempre se está haciendo a través de los signos que circulan por el aro de la comunicación, propiciando una afluencia semántica bajo diferentes niveles y modalidades de aprehensión, donde es la vida, su dureza y esperanza la que entona y poetiza el compromiso verdadera y heroicamente humano.

Delirar sobre el Chimborazo, o sobre cualquier otra cima, montaña, atardecer, fenómeno o suceso de la naturaleza, no significa enajenarse en el estético destello, profanando adjetivos y hablando con lo inexistente. Por el contrario, hace ver la más acicalada lucidez del entendimiento que trae sobre sí la límpida conciencia frente a la realidad y sus desafueros, contribuyendo a que cada pensamiento sea la fonética de la verdad colectiva anunciada por una voz intérprete y traductora de "la claridad del día, el vigor de las formas vegetales, las plantas, el variado plumaje de las aves" (Von Humboldt, 1991, p. XXVII), todo lo que anuncia "el gran carácter de la naturaleza" (Ibíd., p. XXVII).

\section{REFERENCIAS}

Bolívar, S. (1971). Escritos políticos. Madrid: Alianza Editorial.

Bolívar, S. (1978). Obras completas. Tomo V. Colombia: Fundación para la investigación y la Cultura. Compilación y notas de Vicente Lecuna, con la colaboración de la señorita Esther Burret de Nagariz.

Von Humboldt, A. (1991). Viaje a las regiones equinocciales del Nuevo Continente. Venezuela: Monte Ávila Latinoamericana, C.A.

De Zubiría, R. (1983). Breviario del Libertador. Medellín: Bedout.

Foucault, M. (1994). La hermenéutica del sujeto. Madrid: La Piqueta.

Guzmán, G., Fals, O. \& Umaña, E. (1980). La violencia en Colombia. Tomo I. Bogotá: Carlos Valencia Editores.

Lenin, V. (1917). El imperialismo, fase superior del capitalismo. Moscú: Editorial Progreso. 
Ortega y Gasset, J. (1958). La historia como sistema. Madrid: Colección El Arquero.

Ortega y Gasset, J. (1965). Meditación de la técnica. Madrid: Espasa-Calpe S.A.

Ortega y Gasset, J. (1994). Obras completas. Tomos I, II, III, IV, V, VI, VII, VIII, IX, X Madrid: Alianza Editorial.

RoIG, A. (1984, Julio). Bolívar y la filosofía de la historia. Ponencia presentada al III Congreso Internacional de Filosofía Latinoamericana. Universidad Santo Tomás. Bogotá.

Russell, B. (1976). La conquista de la felicidad. España: Espasa Calpe. 